\title{
Norwegian Design Principle for High Pressure Tunnels and Shafts: Its Applicability in the Himalaya
}

\section{Krishna Kanta Panthi}

\begin{abstract}
Cost effective, safe and long term sustainable hydropower development is key for the lasting economic growth in the Himalayan region. Increasing pressure towards the use of renewal and environmentally friendly energy for industrial growth and daily household use will force the Himalayan region to exploit hydropower energy more extensively. The traditionally used design approach of fully lined underground waterway system is costly and financially unfeasible as well as an obstacle to attract investment in the hydropower sector in the Himalaya. Hence, more innovative solutions are needed to make hydro generated energy more cost effective and as a sustainable energy solution in the long term. This paper briefly describes the geological set-up of Scandinavia, history of Norwegian Hydropower and reviews the design principle used to develop the underground waterway system in Norway. Brief comments are also made on the applicability of these principles in the Himalayan region. It is anticipated that more discussions will be made in the future on the geo-tectonic environment of the Himalaya and suitability of Norwegian design principle in the Himalayan region.
\end{abstract}

Key words: Tunneling, Himalayan geology, Norwegian design principles, hydropower, Nepal

\section{Introduction}

The design principle developed over time in Norway 1 for underground waterway system of hydropower schemes in general gives lower capital investment and reduced construction times. This design principle considers rock mass itself a natural concrete mass, which is capable to absorb exerted hydrostatic pressure. Tunnel rock support is only used in very needy areas where the rock mass is highly fractured or there exist weaknesses/ fault zones. The principle has been developed mainly based on the long experience of hydropower tunneling in Norway where the geological and geo-tectonic setup are quite different from the conditions prevailing in the Himalaya. This paper briefly highlights about the Scandinavian geology, history of Norwegian hydropower and the main design principle of underground waterway system that has been developed, periodically upgraded and used in Norway. The paper also briefly touches on the geological and geo-tectonic set-up prevailing in the Himalaya.

\section{Geology of Norway}

The Norwegian continent is mainly composed of very old rock formations consisting of pre-Cambrian base rocks and Caledonian anticline formation. Pre-Cambrian rocks are part of the Baltic shield that includes Norway, Sweden, Finland and the north western part of Russia (Figure 1). The dominating rocks originated in the medium and late pre-Cambrian period represent some of the oldest rocks on earth with an age of 800 to 2500 million years old. In the later Devonian period (about 400 million years ago) the tectonic movement brought the Baltic shield in contact with the Greenland plate. The rocks of the Baltic shield in the east were pushed on top of the incoming Greenland plate in the west, which resulted in the formation of the Caledonian mountain range. Further tectonic movement in continental Europe in the
Permian period (some 280 million years ago) caused a rift in the area to the west and north of present Oslo fjord where volcanic rocks are formed in intercalation with Cambro-Silurian sediments. Lifting of the Baltic shield took place in the Tertiary period, which resulted in folding and tilting in the Caledonian mountain range (Hveding, 1992).

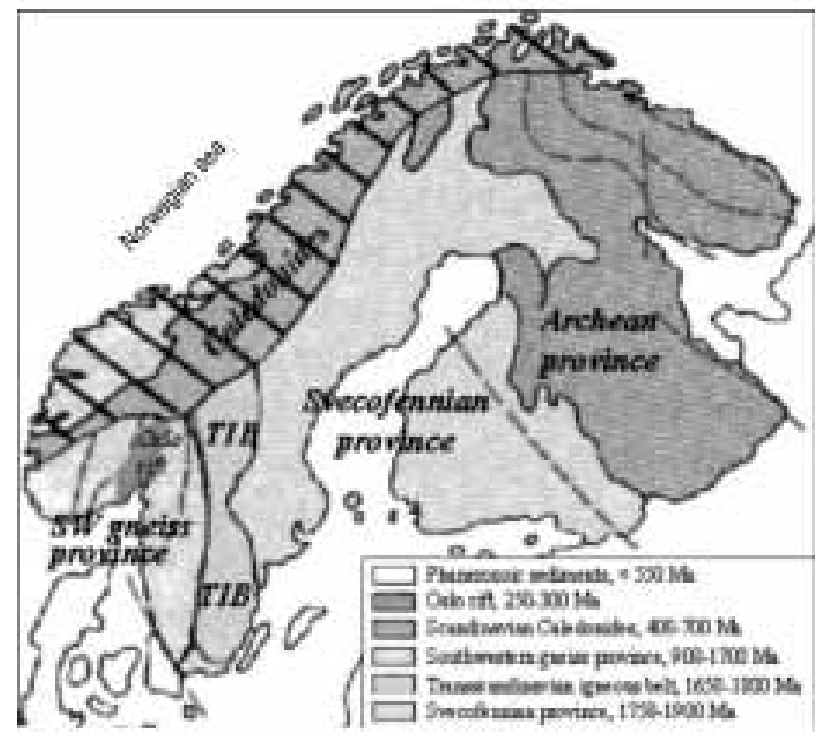

Figure1. Scandinavian geological set-up (slightly modified from NRM, 2013)

From the Cenozoic to recent period (10,000 years ago) de-glaciation occurred, which eroded the overlaying fractured and weathered rock mass. The de-glaciation not only exposed the bed rock mass to the surface but also deep valleys and fjords were formed. Therefore, Scandinavia is considered to be a typical hard rock province consisting predominantly of highly competent old igneous and metamorphic rocks with compressive 
strength > 50 $\mathrm{MPa}$. These old rocks have, however, suffered several periods of earth movements resulting in numerous faults, shear zones and thrust zones (Palmstrom, 1996).

\section{Norwegian Hydropower}

The development of hydropower in Norway has over 150 years of history with many conceptual innovations, challenging and risky decisions made during design and construction periods. About 150 years back, Norway was among the poor nations of Europe and its economy was mainly based on agriculture. In the $1870 \mathrm{~s}$ industrialization process took momentum, and shipping, wood and paper industries slowly started leading towards economic growth. However, quick industrial growth was not possible since Norway could not fullfill the needed energy demand for industrial growth due to insufficient reserve of coal - the most used energy base at that time period.

Upon the introduction of the technology for practical utilization of electricity in the world in the 1880s, fast industrial growth became possible in Norway. The development of industries run by hydropower generated electricity started in the early 1890s. Especially, after Norway announced its independence from Sweden in 1905, the hydropower sector became a backbone for Norway's industrialization ambitions. Hevding (1992) states that by the end of 1939, Norway managed to produce 9.5 TWh hydropower energy annually, which is equivalent to approximately 1,100 MW installed capacity as firm-power. Rapid growth in hydropower development in fact took place only after 1946, in the aftermath of the Second World War.

Topographically, more than 70 percent of Norwegian territory has an elevation exceeding 300 meters, and more than 40 percent land has an altitude exceeding 600 meters. The maximum elevation is about 2,465 meters above mean sea level. Norway is a country with wide mountain valleys or plateaus and consists of numerous natural lakes. Good elevation difference, appreciable precipitation (exceeding 1000 $\mathrm{mm}$ annually), the endowment of many rivers following from the Caledonian mountain range towards the ocean and natural lakes as reservoirs provide an excellent environment for hydropower development in Norway. The potential hydropower energy that is estimated based on annual precipitation exceeds 500 TWh. Out of this huge potential, about 200 TWh is considered to be economically attractive (Hevding, 1992).

As per the statistics (SSB, 2011), out of $128 \mathrm{TWh}$ electrical energy produced in Norway annually in 2011, hydropower contributes over 122 TWh. This is more than 95 percent of total electrical energy produced annually in this country. This is why Norway is known internationally as the country of hydropower. In fact the daily consumption of electricity per inhabitant amounts to about $70 \mathrm{kWh}$ in Norway, which is among the highest in the world. Hence, Norway has long experience in developing hydropower technologies, managing hydropower resources and exploiting the underground space for hydropower development in an optimal and cost effective way.

\section{Use of Underground for Hydropower Development}

The geological conditions are favorable to keep the waterway system of the hydropower scheme underground in Norway. Most of the rocks in the country are of Precambrian and Paleozoic age and the de-glaciation process has helped expose high quality bed rock mass very close to the topographic surface. In addition to favorable geological conditions, the geo-tectonic environment is also a key factor that favors keeping large underground cavern and high pressure tunnels and shafts underground without the use of significant amount of rock support. More importantly, innovative thinking and positive attitude in accepting a certain level of risk in the best possible way by Norwegian technological and engineering communities also played key role in going underground much before than other countries in the world. As a result, most of the Norwegian hydropower schemes are placed underground.

According to Broch (2006), more than 200 powerhouses are located underground and tunnels built as waterways for hydropower schemes exceeds $4000 \mathrm{~km}$ length in Norway. Hence, the Norwegian hydropower industry may in one way be taken as the tunneling industry. It is noted here that during the period between 1960 and 1990 (the peak period of Norwegian hydropower development), more than 100 $\mathrm{km}$ of tunnels were excavated every year. The experience gained through underground excavation for hydropower schemes made it possible to develop advanced tunneling technology in both excavation and support philosophy. Innovative ways of thinking and their realization in real design and construction followed over the years. One such Norwegian innovation is the use of unlined highpressure tunnels and shafts as waterway systems, and another is the development of the so called air cushion surge chamber that has replaced the conventional vented surge chamber in certain topographically difficult hydropower schemes (Figure 2).

These innovative design approaches were possible to be implemented due to the fact that during (1913 to 1917) and shortly after the First World War, there was a shortage of steel in Europe, which caused considerable increase in the steel price. The use of conventional design with almost horizontal headrace tunnel and use of exposed steel penstock along the surface topography all the way down to surface powerhouse as waterway system (upper Figure 2) became too expensive. This forced engineers and technologists to introduce unlined high pressure tunnels and shafts and test the Mother Nature. Four Norwegian hydropower schemes with unlined high pressure tunnels and shafts were built and came into operation during the years 1919-21. In these schemes, static water heads varied from $72 \mathrm{~m}$ to 152m. The Mother Nature's reactions were mixed; i.e. according to Broch (1982) the Skar hydropower project with a static water head of $116 \mathrm{~m}$ was a complete failure, the Toklev hydropower project was operated without 


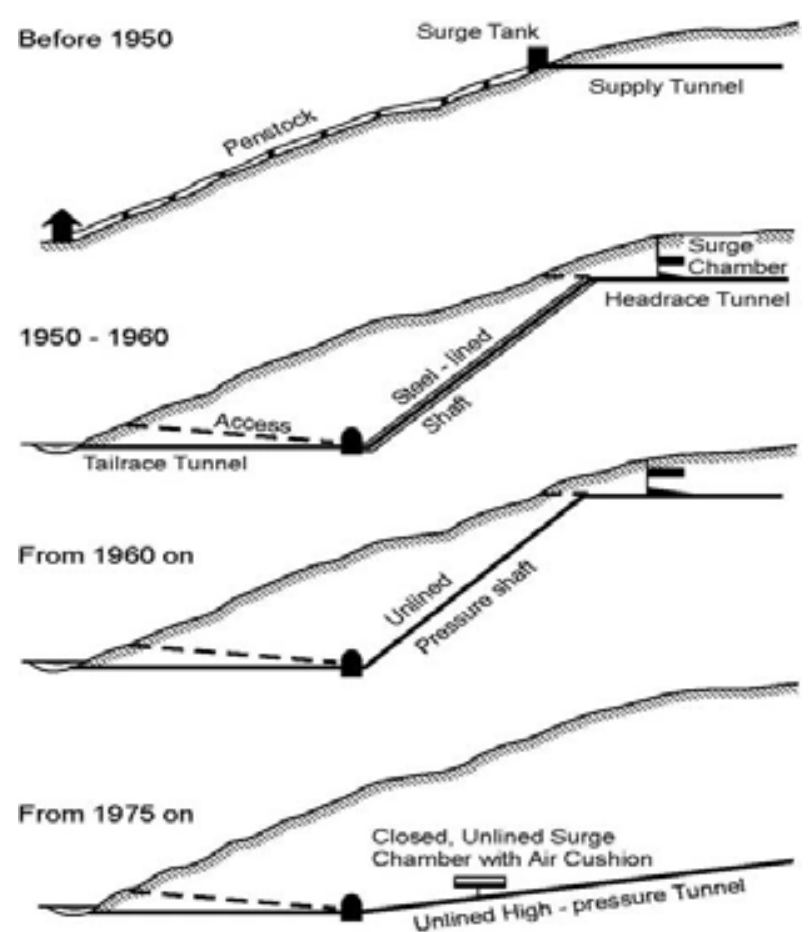

Figure 2. Historic development of lay-out for Norwegian waterway system (Broch, 2006).

any significant problem; the Svelgen with a water head of $152 \mathrm{~m}$ had some minor leakage during the first filling, and the Herlandsfoss with $136 \mathrm{~m}$ static water head had leakage through the low rock cover area.

Even though unlined high pressure tunnels and shafts were tested as early as the 1920s, the traditional approach of keeping the powerhouse above ground with the penstock pipe up to the surge chamber located downstream of the headrace tunnel was continued until the 1950s. It is however noted that there was very little hydropower development activity between 1930 and 1945 due to political instability including the Second World War. The waterway system used in Norway over the past 100 years is presented in Figure 2.

With rapid advances in rock excavation methods and construction equipment, keeping the powerhouse and waterway system underground became an economically attractive solution after the 1950s. As indicated in Figure 2, the high pressure inclined shaft was steel penstock lined until the 1960s, and thereafter the concept of keeping almost the whole waterway system (including high pressure shafts and tunnels) unlined became a tradition in Norway. The oldest unlined pressure shafts have now been in operation for 90 years. Excluding a couple of exceptional cases of partial collapse during the past 10 years (Panthi, 2013), no tunnel and shaft collapses and unacceptable leakage cases have been registered.

\section{Norwegian Design Criteria for High Pressure Tunnels and Shafts}

The key engineering geological factors that directly influence the stability of tunnels and shafts are rock mechanical properties at the vicinity of concern and in- situ stress conditions (Panthi, 2012). Exploiting unlined high pressure tunnels and shafts as indicated in the lower part of Figure 2, therefore, demands two main criteria to be fulfilled. These two criteria are related to both geology and the geo-tectonic environment of the area in concern. Most of the underground waterway system of Norwegian hydropower schemes with unlined high pressure tunnels and shafts have fullfilled these two criteria, and hence confronted no major operation and stability related challenges as such.

\section{Criterion 1: Required geological conditions}

As discussed earlier, Norway is a typical hard rock province consisting of very old rock formations. In addition, the de-glaciation process that ended approximately 10,000 years ago excavated away most of the weathered rock mass that existed at the surface of sloping mountains and valley sides. The major challenges connected to instability in tunnels and shafts due to deep weathering simply do not exist for most of the hydropower schemes built in Norway. In addition, the rock mass in general is massive with high class rock quality and less fracture intensity.

The rock mass itself is in fact a natural concrete. If it is massive with no significant fracturing, the rock mass may be exploited as natural concrete capable of resisting the load exerted on it. However, it is noted here that this environment is not met always and there are exceptions. Even in Norwegian Hydropower Schemes, there are always segments of tunnels and shafts where weakness and shear zones are crossed, where special rock support measures have been applied to secure stability. There are certain considerations that must be taken care of or even avoided. According to Nilsen and Thidemann (1992), following are the unfavorable geological conditions for the use of unlined high pressure tunnels and shafts, which are recommended to be avoided while selecting the alignment;

1. High porosity rocks of volcanic and sedimentary origin.

2. Areas with Karstic phenomenon.

3. High degree of jointing in the rock mass having open and inter-communicating joints.

4. Weakness and fault zones with unfavorable orientation.

5. Impermeable clay bands that may cause high water pressure built up in critical locations.

Hence, comprehensive and thorough engineering geological investigations were carried out before an unlined high pressure tunnel and shaft solution was proposed in Norway.

\section{Criterion 2: Geo-tectonic environment}

The rock masses are subjected to in-situ stresses due to gravity and the geo-tectonic environment surrounding them. The tectonic contribution on the magnitude of horizontal stresses is considerable if the rock masses in 
the area of concern are relatively unjointed and massive in strata. On the other hand, if the rock mass is fractured, schistose, sheared, deformed and thinly foliated/ bedded, the de-stressing occurs and the tectonic contribution on the magnitude of the total horizontal stresses reduces drastically. This results in a decrease in the confinement in the rock mass and an-isotropic in-situ stress condition. Therefore, geo-tectonic environment in the vicinity of concern is extremely important regarding the exploitation of unlined high pressure tunnel and shaft. In addition, there is a topographic effect on the overall distribution of principle stresses of the locality.

Tectonically, the Scandinavian shield is much more stabilized than the Himalaya. Hence, the seismic activity in the continent is relatively low and the earthquakes are of magnitude mostly less than 4 on the Richter scale. On top of that, the de-glaciation took off the weathered rock mass, which resulted in a rebound to the massive rock mass due to downloading. As a result, the tectonic components of horizontal stresses are rather high in Scandinavia (particularly in Norway). Many stress measurements carried out in this country indicate that the horizontal stress magnitudes are mostly higher than $10 \mathrm{MPa}$, and they may reach well up to $30 \mathrm{MPa}$. High horizontal stress provided a favorable environment to keep high pressure tunnels and shafts unlined.

The mixed experiences gained from four unlined pressure shafts built in the 1920 s have been pivotal in correctly understanding the geo-tectonic environment of the Scandinavian shield particularly after the 1960s. This understanding led to develop design criteria associated with in-situ stress conditions, which are famously known as Norwegian Rules of Thumbs. The Rules of Thumbs that were developed in the 1960 s and are related to the topographic condition of the valley sides (Nilsen and Tidemann, 1992), which are expressed in Figure 3 and Equations 1 and 2 below.

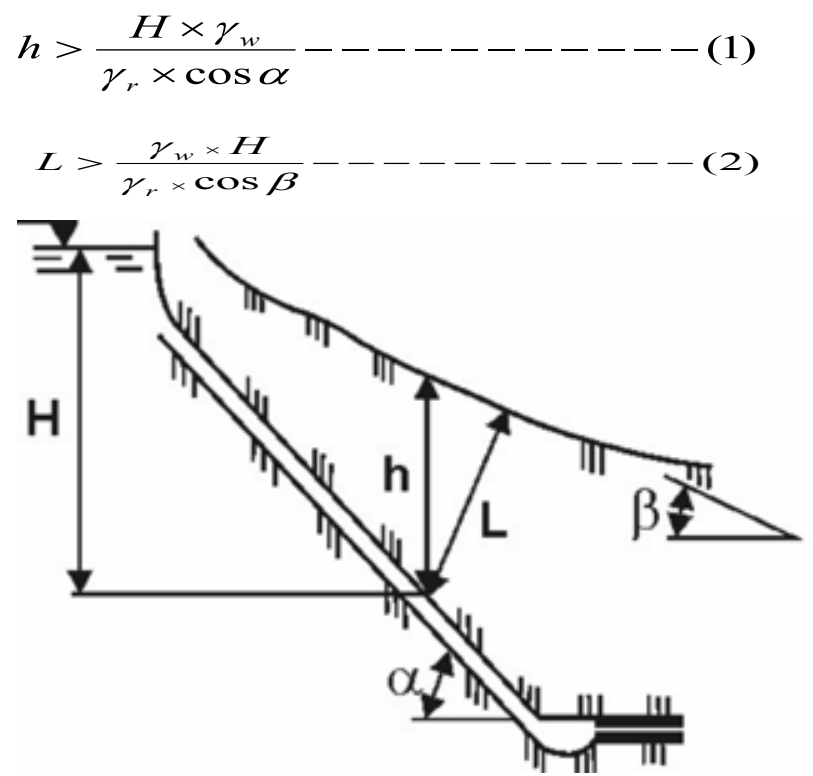

Figure 3. Illustration expressing topographic requirement in Norwegian Rule of Thumbs.
Where; $h$ is the vertical depth of the point of study $(\mathrm{m}), \mathrm{L}$ is the shortest distance between the surface and the point of study (m), $\alpha$ is the inclination of the pressure tunnel or shaft, $\beta$ is the average available inclination of the valley side, $H$ is the static water head $(m), \gamma_{r}$ is the specific weight of rock and $\gamma_{w}$ is the specific weight of water.

These old rules of thumbs represent simple limit equilibrium methods that account for only the vertical gravitational stresses. However, the overall stress situation in the vicinity of concern is highly influenced by the geo-tectonic environment, meaning by both vertical and horizontal stresses. Along the valley side slopes, these vertical and horizontal stresses are resolved following the valley side slope and perpendicular to it. Hence, the best way to express the finite element method is to consider the minimum principle stress $\sigma_{3}$ as the deciding factor for whether unlined high pressure tunnels and shafts are possible or not, which is expressed by the Equation 3 as given below;

$$
\sigma_{3}>H \times \gamma_{w}----------- \text { (3) }
$$

The technology of today allows us to exploit numerical modelling tools extensively, which can be used to check the requirement expressed in Equation 3.

\section{Applicability of Norwegian Criterion in the Himalaya}

The rock mass of the Himalaya excluding the Siwaliks are also very old; i.e. older than the Paleozoic age (more than 400 million years old). However, weathering and fracturing are intense along the topographic slopes and valleys of the Himalaya leading to deep weathering. In addition, the geo-tectonic environment in the Himalayan region is very different than that of Scandinavia. Himalaya is prone to recent tectonic evolution and the mountains in building process. Hence, the seismic activity in the Himalaya is very intense. Even though, the tectonic push of the Indian plate towards the north produces considerable horizontal tectonic stress, the large scale earthquakes de-stress the accumulated stresses in the rock mass. This certainly influences the overall magnitude of horizontal tectonic stress and varies greatly in the Himalaya. The horizontal stress magnitude greatly depends on the geo-tectonic environment in the surrounding area (Panthi, 2012). A more detailed study is necessary to understand the geo-tectonic environment of the region, which is believed to be useful for adapting the Norwegian design principles in the Himalaya.

\section{Conclusion}

A brief review of the geological set-up of the Scandinavian shield has been made, and the design principles developed in Norway for the use of unlined high pressure tunnels and shafts discussed. It is concluded that there are considerable differences between both the geological and geo-tectonic environments prevailing in Scandinavia and the Himalaya. It is concluded that more exploration and research need to be carried out in the future 
to examine to what extent these design principles can be used so that more cost effective, safe and long-term sustainable underground high pressure tunnels and shafts as waterway systems are practiced in the Himalaya.

$$
\text { - - }
$$

Krishna Kanta Panthi, $P h D$, is an Associate Professor in Geological Engineering in the Department of Geology and Mineral Resources Engineering, Norwegian University and Science and Technology (NTNU), Trondheim, Norway. He has completed his Dr. Ing. degree on the 'Analysis of Engineering Uncertainties Related to Tunneling in the Himalayan Rock Mass Conditions' in 2006 from NTNU. He completed his M.Sc. in Hydropower Development in 1998 and M.Sc. in Civil Engineering in 1992. He is the author of many scientific papers related to tunneling, rock slope engineering and hydropower. He has over 15 years of experience in the design, construction and planning of tunneling and hydropower projects in the Himalaya (Nepal and India).

Corresponding address: krishna.panthi@ntnu.no

\section{References}

Hveding V. 1992. Hydropower development in Norway.
Hydropower Development, series no. 1. Department of Hydraulic Engineering, Norwegian Institute of Technology, p.83.

Nilsen B. and Thidemann A. 1992. Rock Engineering. Hydropower Development, series no. 9. Department of Hydraulic Engineering, Norwegian Institute of Technology, p.156.

Naturhistoriska Riksmuseet (NRM). 2013. http://www. nrm.se/english (viewed on 10.12.2013).

Palmstrom A. 1989. Geology of Norway. Norwegian Soil and Rock Engineering Association, publication no. 6.

Palmstrom A. 1996. Engineering geology and rock engineering applied in the design of Norwegian tunnels. Proceedings: Tunnels for the third Millennium, 16p.

Panthi K. K. 2012. Evaluation of rock bursting phenomena in a tunnel in the Himalaya. Bulletin of Engineering Geology and the Environment, Vol. 71, pp. 761 - 769.

Panthi K. K. 2013. Collapse and burst debris flood at Svandalflona. Norwegian Tunneling Society, Publication 12, pp. 117 - 123.

Statistics Norway (SSB). 2011. www.ssb.no/en (viewed on 11.12.2013).
Continued From page 26

Corresponding address: subash_life@hotmail.com

Manish Lamsal is a final year undergraduate student in Mechanical Engineering Department at KU. He is involved in several project activities at TTL.

Corresponding address: lamsalmanish9o@gmail.com

Bhola Thapa is a supervisor for this study. He is a professor in Mechanical Engineering Department and also Registrar at KU. He obtained his PhD in Mechanical Engineering at the Norwegian University of Science and Technology in (NTNU) 2004. His research area is Sand Erosion of Hydraulic Machinery.

Corresponding address: bhola@ku.edu.np

Biraj Singh Thapa is a co-supervisor for this study. He has also worked as Faculty In-charge of Turbine Testing Lab in Mechanical Engineering Department at Kathmandu University. He holds MS Research Degree in Design of Francis turbines. He has been involved in several $R \& D$ and professional projects to design and develop Francis turbines. Currently, he is doing his PhD at NTNU.

Corresponding address: biraj.s.thapa@ntnu.no

All the authours are associated with Turbine Testing Lab, School of Engineering, K. U, Nepal.

\section{References}

Brekke H, 2010, State of the art in turbine design, Water power laboratory, NTNU publications, Trondheim,
Norway.

Department of Electricity Development (DoED), 2012, Applications for Survey License (Below $1 \mathrm{MW}$ ).

URL:http://www.doed.gov.np/application-survey_ license_for_generation_below-1mw.php

Environmental Resources Group Ltd (ERG)., 2012, Hydropower. URL: http://www.erg.com.np/ hydropower_national.php

Erichsen HP, 2011, Mechanical design of Francis turbine exposed to sediment erosion, Waterpower Laboratory, NTNU publications, Trondheim, Norway.

Kjølle A, 2001, Hydropower in Norway: Mechanical Equipment, in Proceedings of the IAHR Congress, Trondheim, Norway.

Turbine Testing Lab (TTL), 2013, Feasibility Study for Turbine Manufacturing and Testing Facility in Nepal, Technical Report submitted to NORAD. URL: http:// ku.edu.np/ttl/index.php/rresearch?id=86

Thapa BS, Thapa B, Dahlhaug OG, 2012, Current research in hydraulic turbines for handling sediments. Energy 47, Issue 1, pp. 62-69.

Wei Z, Finstad PH, Olimstad G, Walseth E, Eltvik M, 2009, High Pressure Hydraulic Machinery, PhD Thesis, Water power Laboratory, Norwegian Institute of Science and Technology.

\section{Foot Note:}

1. The Hydraulic Turbine selection computer program runs at an interface created by the codes generated in $\mathrm{C}++$ programming language. 